\title{
Utilitarian or Experiential? An Analysis of Usability Questionnaires
}

\author{
Tet Kun Chung and Noraidah Sahari
}

\begin{abstract}
This article aims to analyze current usability questionnaires in terms of their evaluation of utilitarian and experiential attribute in usability. Supported by item analysis of questions from 11 usability questionnaires into three categories of utilitarian, experiential aesthetic and experiential hedonic, a conceptual review of the questionnaire has pointed out current trend in usability questionnaire focus more on evaluating utilitarian aspect of a system. Although more experiential measurements were derived from recent developed questionnaires but the focus still remain on judging usability based on the performance of software. The result of this article also suggested Usefulness, Satisfaction and Ease of use (USE) questionnaire which have a fair choice of questions for measuring system usability based on performance without neglecting user experience.
\end{abstract}

Index Terms-Experiential, questionnaire, usability, utilitarian.

\section{INTRODUCTION}

Usability is a widely explored field in current study of information science as usability itself is a quality attribute of a product that will be taken into serious consideration when deciding whether a system or product is worth the time, effort and money to invest into or not. Usually, investment in computer systems and software aimed to be helpful in the management or production process of an organization or individual but when usage is trivial or does not meet the expected quality and satisfaction or even frustrate the user, then that investment will only be a burden or a waste. Then there are also a lot of systems and software where developer themselves claimed that their products are usable and were tested using various usability evaluation method which all seems so promising and yet no guarantee that it will definitely provide a great user experience. This happened because most people do not understand how usability test were conducted, what were measured and why it was measured in that manner. This article will seek to understand what were measured in usability questionnaires and by that provides a better understanding of what to be expected from a product that were usability certified using the corresponding questionnaires analyzed here.

\section{LITERATURE REVIEW}

\section{A. Usability - ISO}

What is usability? This would be a difficult question even for the usability expert out there. In the perspective of the

Manuscript received March 20, 2014; revised May 15, 2014.

Tet Kun Chung is with National University of Malaysia, Bangi, 43600, Malaysia (e-mail: tetkun@ hotmail.com).
ISO, defining usability is still an ongoing process from the beginning of ISO 9241 to ISO 9126 and now ISO/ICE 25010 and yet a final conclusion upon how to define usability in order to measure it still an ongoing process. In an article by Hertzum and Clemmensen [1] upon how do usability professionals construe usability, they discover that even usability professionals experience considerable uncertainties upon the meaning of usability that their current conceptions of usability are fragmented and vague. From Hertzum and Clemmensen's research also, they pointed out that while current usability professionals have made used of more utilitarian then experiential construct, their experiential constructs still go beyond what is define in ISO 9241. The following are a short background of ISO declaration of usability for both lab and industry use.

\section{1) ISO 9241-11:1998 (Guidance on usability)}

The International Organization for Standardization have set a definition for usability since the year 1998 based on the notion of providing essential guidance for developer and researcher to a general definition on usability. The ISO 9241-11 define usability as the:

"Extent to which a product can be used by specified users to achieve specified goals with effectiveness, efficiency and satisfaction in a specified context of use."

The keywords for usability in this definition are effectiveness, efficiency and satisfaction. A lot of current research and usability testing method are based on this definition which sought to improve usability of a system or products in terms the three domains mentioned above. As same as the problem faced by various usability experts, the use of ISO 9241 was not enough to accommodate to the requirement and implementation of usability approach which has shifted from testing and evaluating finished product to designing usability evaluation into the architecture of software development. This has given a path to the development of the next ISO standard.

\section{2) ISO 9126 (2001)}

The ISO 9126 has a different classification for usability. It comprises four part and usability has become one of the six characteristic based on the quality model in ISO 9126-1 which are functionality, reliability, usability, efficiency, maintainability and portability. Usability is then sub categorized into five aspects of learnability, understandability, operability, attractiveness and usability compliance. A rather different approach in defining usability has been taken in ISO 9126 where usability itself has become one of the quality attribute of a system or software. The measurement of software usability recommended in ISO 9126-2 where 28 external metrics which represent the quality characteristic of usability. From an article on harmonization of usability measurements in ISO 9126 by Cheikhi, Abran, 
and Suryn [2], a table of which the 28 metric was classified under sub characteristic of usability in the ISO 9126-2 given below:

TABLE I: THE USABILITY METRIC IN ISO 9126-2

\begin{tabular}{|l|c|}
\hline Usability sub -characteristics & External Quality Measures \\
\hline Understandability & 7 \\
\hline Learnability & 6 \\
\hline Operability & 12 \\
\hline Attractiveness & 2 \\
\hline Usability Compliance & 1 \\
\hline Total & 28 \\
\hline
\end{tabular}

The way of categorizing usability under a quality model and same level as functionality, reliability, efficiency, maintainability and portability produce a more complex and different definition than the well accepted ISO 9214. Although it was revised in the year 2001, ISO 9126 was not a favorite option among usability expert which lead to a newer version of the standard.

\section{3) ISO/IEC 25010:2011}

The International Organization of Standardization (ISO) and the International Electrotechnical Commission (ICE) have established a joint technical committee to collaborate in the fields of usability to produce a revised version of ISO/ICE 9126-1:2001, the ISO/ICE 25010. In this standard, instead of six there are eight product quality characteristics and $31 \mathrm{sub}$ characteristic in contrast with 27 sub characteristic in ISO 9126. The eight quality characteristics are of functionality suitability, performance efficiency, compatibility, usability, reliability, security, maintainability and portability. In the usability section, there are two new sub characteristics of user error protection and accessibility also understandability is renamed appropriateness recognizability, and attractiveness is renamed user interface aesthetics.

Though outline for usability definition in ISO was not as grand and important as ones might regard it as a sole attribute that determine the overall quality and performance of a system or software but recent researcher still regard usability as a special and separate entity worth their utmost attention and deep exploration. This was led by the notion of understanding usability based on user experience.

\section{B. Usability, Aesthetic and Hedonic}

Over the year, researchers have regard usability as a bigger portion occupying the whole picture of product quality and user experience. Researchers such as Mahlke and Thüring [3] in their research upon emotional experience in experiential context suggest that user's overall judgments of the systems involve both instrumental (utilitarian) and non-instrumental (aesthetics) qualities. Tractinsky and Zmiri [4] also support the same notion which suggested that knowledge on instrumentality, aesthetics, and symbolism can help to better understand how applications are evaluated by user. Trends in usability research have started to capture the effect of aesthetics value with empirical studies that suggested aesthetic aspect of various computing systems played an important role in overall user attitudes and experience (e.g., [5]-[9]) which leads to the research that try to determine the relationship between usability and aesthetics (e.g., [10]-[12]). Though ISO/IEC 25010 has set out a standard classification of usability under the quality model, it is still a very complex model that covers too much for the notion of just quality of a product. Researchers are still looking for a better definition of software usability and a more comprehensive method of evaluating usability.

\section{Usability Evaluation Method}

There are currently an abundant method to evaluate usability that was produced by various institutions and organizations for the purpose of determining the level of usability for wide range of systems, software and products. Since evaluation of usability is context bounded, then there is no best method or one method to evaluate the usability of every product. Based upon a systematic mapping of usability test upon website for 14 years from various research article by Fernandez, Insfran, and Abrahão [13], there are five categories of usability evaluation method which are user testing method that sub categorized by think-aloud protocol, question-asking protocol, performance measurement, log analysis and remote testing; secondly inspection methods which include heuristic evaluation, cognitive walkthrough, perspective-based inspection and guideline review; thirdly inquiry methods which comprise of questionnaire, interviews and focus group; fourthly analytical modeling which consists of methods such as cognitive task analysis, task environment analysis and GOMS (Goals, Operators, Methods and Selection) analysis; lastly simulation method.

For the purpose of this conceptual review article, we are going to discuss on the widely used and empirical method of usability survey questionnaire. There are a lot of questionnaires currently available in the internet whether it's free or require a subscription fees for systems or websites. Most of these questionnaire focuses in measuring the three aspect of usability which are effectiveness, efficiency and satisfaction as suggested in the ISO 9241.

\section{Usability Questionnaire}

Usability questionnaire was firstly developed for industrial mean by company such as IBM with aims to increase the usability of their products. IBM's work in usability questionnaire can be dated back to the year 1979 until today and the company still acts as a major contributor in the field of usability studies. The renowned usability questionnaires from this company are of the After-Scenario Questionnaires (ASQ), the Printer-Scenario Questionnaire (PSQ), the Post-Study System Usability Questionnaire (PSSUQ) and the Computer System Usability Questionnaire (CSUQ) [14]. Following the work from IBM and the advancement of information technology products, researcher and institute have started to come up with their own brand of usability questionnaires. Such as the System Usability Scale (SUS) by John Brooke from Digital Equipment Corporation; the Questionnaire for User Interaction Satisfaction (QUIS) by Ben Shneiderman at University of Maryland; the Software Usability Measurement Inventory (SUMI) by Jurek Kirakowsi at University of Cork; the Usefulness, Satisfaction and Ease of use by Arnold M. Lund from Sapient and so on.

The main issue when using questionnaire in the usability evaluation is that whether it is enough to only use survey as user experience are very subjective and orientate differently for each person. To address that matter, some usability questionnaire have gone through the process of psychometric 
evaluation to help strengthen the reliability and validity of those questionnaires (e.g., [15], [16]), but there are others still rely on Alpha Cronbach value to support the reliability of their questionnaire. Though it may seems that questionnaires are not adequate to be used as the only method for evaluating usability based on its complex structure and subjective issue but in the industrial practice, questionnaire have been helping software engineer and manufacturer to solve their usability crisis.

\section{METHOD}

This conceptual review of questionnaire is based on the work of Law, van Schaik, and Roto [17] upon answering the basic question of whether usability is measureable or not. They conducted a research that involved questionnaire and interview to classify a set of attribute used for measuring usability into the measureable and non-measureable domain. Their work are based on a CUE (Components of User Experience) model developed by Thüring and Mahlke [18] which study the usability, aesthetic and emotions in action to influence why some user might prefer some systems over others. The CUE model was a pioneer model in explaining the relationship between performance and affective part of a usability evaluation. Based on the work of Law, van Schaik and Roto, a list of words which that occur in usability questionnaires was identified and classified to the three domain of utilitarian, experiential aesthetic and experiential hedonic as presented below:

\section{A. Instrumental Qualities (Utilitarian)}

Benefit, Clarity, Comfort, Control, Ease of use, Efficiency, Intuitiveness, Learnability, Reliability, Responsiveness, Response Time, Smoothness, Speed, Time on task, Usability, Usefulness.

\section{B. Non-Instrumental Qualities (Experiential-Aesthetics)}

Attractive, Beauty, Challenge, Cool, Creative, Desirability, Meaning, Stimulation.

\section{Short-Term Affective Response (Experiential-Hedonic)}

Affect, Annoyance, Anxiety, Arousal, Attachment, Delight, Disgust, Engagement, Enjoyment, Excitement, Fear, Flow, Frustration, Fun, Immersion, Joy, Physical Pain, Pleasure, Stress, Surprise.

\section{Long-Term Evaluation Response (Experiential-Hedonic)}

Competence, Expectation, Happiness, Love, Motivation, Need Fulfillment, Preference, Relatedness, Satisfaction, Trust.

The suggested list was used as it was except for the word "Comfort" which we found more suitable in the experiential hedonic domain rather than the utilitarian domain.

Although it may look like a lot of related wording from the above list but it was not sufficient enough to be used as a complete list to analyze all the 11 usability questionnaires, therefore an additional list was developed with the help of Microsoft Word's thesaurus function in defining words with similar meaning to the listed ones from of Law, van Schaik and Roto [17]. The list of the words can be observed in the appendix part of this article.
A total of 11 usability questionnaires was analyze to identify each question whether it belongs to the utilitarian domain or the experiential domain where experiential domain are then divided into two sub group of aesthetic and hedonic. Those 11 questionnaires are presented in the table below.

TABLE II: THE DETAILS OF THE 11 USABILITY QUESTIONNAIRES

\begin{tabular}{|c|c|c|c|}
\hline Acronym & Instrument & Reference & Example \\
\hline QUIS & $\begin{array}{l}\text { Questionnaire for User } \\
\text { Interface Satisfaction }\end{array}$ & Chin et al, 1988 & $\begin{array}{c}27 \\
\text { questions }\end{array}$ \\
\hline PUEU & $\begin{array}{l}\text { Perceived Usefulness } \\
\text { and Ease of Use }\end{array}$ & Davis, 1989 & $\begin{array}{c}12 \\
\text { questions }\end{array}$ \\
\hline NAU & $\begin{array}{l}\text { Nielsen's Attributes of } \\
\text { Usability }\end{array}$ & Nielsen, 1993 & $\begin{array}{c}5 \\
\text { attributes }\end{array}$ \\
\hline NHE & $\begin{array}{l}\text { Nielsen's Heuristic } \\
\text { Evaluation }\end{array}$ & Nielsen, 1993 & $\begin{array}{c}10 \\
\text { heuristics }\end{array}$ \\
\hline PSSUQ & $\begin{array}{l}\text { Post-Study System } \\
\text { Usability } \\
\text { Questionnaire }\end{array}$ & Lewis, 1995 & $\begin{array}{c}19 \\
\text { questions }\end{array}$ \\
\hline ASQ & $\begin{array}{l}\text { After Scenario } \\
\text { Questionnaire }\end{array}$ & Lewis, 1995 & $\begin{array}{c}3 \\
\text { questions }\end{array}$ \\
\hline PHUE & $\begin{array}{l}\text { Practical Heuristics for } \\
\text { Usability Evaluation }\end{array}$ & Perlman, 1997 & $\begin{array}{c}13 \\
\text { heuristics }\end{array}$ \\
\hline PUTQ & $\begin{array}{l}\text { Purdue Usability } \\
\text { Testing Questionnaire }\end{array}$ & Lin et al, 1997 & $\begin{array}{c}100 \\
\text { questions }\end{array}$ \\
\hline USE & $\begin{array}{l}\text { Usefulness, } \\
\text { Satisfaction, Ease of } \\
\text { use }\end{array}$ & Lund, 2001 & $\begin{array}{c}30 \\
\text { questions }\end{array}$ \\
\hline SUS & System Usability Scale & Brooke, 1986 & $\begin{array}{c}10 \\
\text { questions }\end{array}$ \\
\hline SUMI & $\begin{array}{l}\text { System Usability } \\
\text { Measurement } \\
\text { Inventory }\end{array}$ & $\begin{array}{l}\text { Kirakowski, } \\
1994\end{array}$ & $\begin{array}{c}50 \\
\text { questions }\end{array}$ \\
\hline
\end{tabular}

To ensure the validity of the analyzed outcome, the classification of the questionnaire will then be verified by two usability experts whom are currently lecturer from National University of Malaysia. They will be given a survey form listing all the classification done with a Likert scale of 5 intervals to show their degree of agreement based on what was categorized for each questionnaires. The survey will then be used to confirm the categorizing of each question.

For items that contradicted with the initial classification, a discussion with the two lecturers will then be conducted to reach a final decision. All classification will be based on the work of Law, van Schaik, and Roto [17] and the extended list obtained from Microsoft Word's thesaurus.

\section{RESUlts}

TABLE III: THE ITEM ANALYSIS OF THE 11 USABILITY QUESTIONNAIRES

\begin{tabular}{|c|c|c|c|c|}
\hline \multirow{2}{*}{ Usability Measure } & \multirow{2}{*}{$\mathrm{U}$} & \multicolumn{2}{|c|}{$\mathrm{E}$} & \multirow{2}{*}{ Sum } \\
\hline & & $\mathrm{A}$ & $\mathrm{H}$ & \\
\hline SUS (Brooke, 1986) & 8 & 0 & 2 & 10 \\
\hline QUIS (Chin et al, 1988) & 24 & 1 & 2 & 27 \\
\hline PUEU (Davis, 1989) & 12 & 0 & 0 & 12 \\
\hline NAU (Nielsen, 1993) & 4 & 0 & 1 & 5 \\
\hline NHE (Nielsen, 1993) & 10 & 0 & 0 & 10 \\
\hline SUMI (Kirakowski, 1994) & 36 & 1 & 13 & 50 \\
\hline ASQ (Lewis, 1995) & 3 & 0 & 3 & 6 \\
\hline PSSUQ (Lewis, 1995) & 13 & 0 & 6 & 19 \\
\hline PUTQ (Lin et al, 1997) & 100 & 0 & 0 & 100 \\
\hline PHUE (Perlman, 1997) & 13 & 0 & 0 & 13 \\
\hline USE (Lund, 2001) & 19 & 0 & 11 & 30 \\
\hline
\end{tabular}


The above table shows the 11 questionnaires being categorized under the domain of utilitarian and experiential. Experiential can then be distinctively sub-divided into two sub category of aesthetic and hedonic value while utilitarian will not be divided into any sub groups and will act as the category that represents the performance aspect of the measurement in justifying effectiveness, efficiency, learnability and memorability of a system. The satisfaction of a system is being measured by the experiential part of the questionnaires. The following is the percentage of the tabulation above under the same classifications.

TABLE IV: THE PERCENTAGE OF U, EA AND EH

\begin{tabular}{|l|c|c|c|}
\hline \multirow{2}{*}{ Usability Measure } & \multirow{2}{*}{ U\% } & \multicolumn{2}{|c|}{$\mathrm{E}$} \\
\cline { 3 - 4 } & & $\mathrm{A} \%$ & $\mathrm{H} \%$ \\
\hline SUS (Brooke, 1986) & 80.00 & 0 & 20.00 \\
\hline QUIS (Chin et al, 1988) & 88.89 & 3.70 & 7.41 \\
\hline PUEU (Davis, 1989) & 100.00 & 0 & 0 \\
\hline NAU (Nielsen, 1993) & 80.00 & 0 & 20.00 \\
\hline NHE (Nielsen, 1993) & 100.00 & 0 & 0 \\
\hline SUMI (Kirakowski, 1994) & 72.00 & 2.00 & 26.00 \\
\hline ASQ (Lewis, 1995) & 50.00 & 0 & 50.00 \\
\hline PSSUQ (Lewis, 1995) & 68.42 & 0 & 31.58 \\
\hline PUTQ (Lin et al, 1997) & 100.00 & 0 & 0 \\
\hline PHUE (Perlman, 1997) & 100.00 & 0 & 0 \\
\hline USE (Lund, 2001) & 63.33 & 0 & 36.67 \\
\hline
\end{tabular}

From the table above, it is recognized from the 11 popular usability questionnaires, there are four usability questionnaires that fully measure the utilitarian part of usability which are of PUTQ, PUEU, NHE and PHUE. The rest of the questionnaire tends to measure both utilitarian and experiential attribute of a product with focus mainly on utilitarian attributes are of those QUIS, NAU, SUS, PSSUQ, USE, ASQ and SUMI. There are only two questionnaires which measure the aesthetic attribute of experiential domain which are QUIS and SUMI.

From the table also, it is recognized that the USE questionnaire have the highest proportion of measurements upon experiential domain compared to other questionnaires with an overall of 11 out of $30(36.67 \%)$ questions was upon experiential issues. Similar to USE are the PSSUQ and SUMI which both are very popular questionnaires being used in current usability evaluation with 6 out of $19(31.58 \%)$ and 14 out of $50(28 \%)$ questions respectively focus on experiential issue of a software. The SUMI questionnaire also includes one aesthetic attribute which are not presented in USE or PSSUQ questionnaires.

Another trend that can be noticed from the above table is the trend of incorporating experiential measure in the usability test to date. With the current usability measure, USE consist of $36.67 \%$ of its questions of experiential domain shows a shift on the experiential domain in usability testing. This is coherent to the research trends in aesthetic and hedonic value which can be traced back since the year 1997 (e.g., [5] - [12]).

\section{Discussions}

The above shows the item analysis of usability survey to date, it focused on standardize questionnaire and disregard those of homebrew because standard questionnaire had gone through the necessary process to ensure that the questionnaire are well crafted to be reliable, valid and sensitive (e.g., [19], [20]). The comparison above also disregards usability questionnaires that are specially developed for specific choice of system or product such as the Website Analysis and Measurement Inventor (WAMMI) questionnaire.

Based on the results, shown from Table II, we can notice that most questionnaire have items 30 or less with exceptions to the SUMI and PUTQ questionnaires. This suggested that most questionnaires are using single item approach in investigating the usability of a product which opposed what was suggested by Churchill Jr [21]. Though multiple questionnaires tend to have higher reliability and validity but work from Christophersen and Konradt [22] revealed that single item questionnaire are more popular and cost effective with adequate reliability while highly correlating with those of multiple questionnaire.

Another pattern can be noticed from table above is the more apparent focus on experiential metric in usability measures. Despite the convoluted definition of usability under ISO 9126, researcher still tends to regard aesthetic and hedonic value as important aspects of usability. Various researches was conducted over the years to justify the relationship among them and the CUE model is one of the model that was developed to help other usability researcher to further evaluate the significance of the aesthetics and hedonic attribute in usability.

We can notice that aesthetics was not given apparent attentions in usability questionnaire (see Table IV). From the CUE model, utility and aesthetics attribute will contribute to affective value and then effect the overall perceive usability of a system or product but only two questionnaires of QUIS and SUMI have only one question correspond to aesthetic value of a system or product. Though one may say that during the time these questionnaires were developed, aesthetic was not yet identify as an important attribute of usability but research from Tuch et al. [11] on understanding the relationship among usability, aesthetics and affective confirm that aesthetics does not affect perceived usability but in turn the frustration of poor usability lowers ratings on perceived aesthetics. This may explains why most questionnaires do not focus much on aesthetic value but starting to pay attentions to hedonic value that represent the satisfaction level in usability evaluation.

Though this article is supported by a rather limited empirical analysis but the amount of research and attentions given to the above questionnaire has leads to the notion of what have been integrated in these questions and analyzing it under three categories of utilitarian, experiential aesthetic and experiential hedonic will help to give some insight and supporting facts upon understanding what lies within the CUE model.

\section{CONCLUSIONS}

This paper provide some analysis of usability survey current to date and tries to understand how usability practitioner develop usability questionnaire with respect to the three attribute of utilitarian, experiential aesthetic and 
experiential hedonic and a simple frequency analysis. It seems that usability at the beginning was very utilitarian oriented and slowly to progress the evaluation of the aesthetic and hedonic value that was recently regard as an important aspect of perceived usability. Though the analysis does support what was to be concluded by many researcher that hedonic value does take part in influencing perceived usability but analysis also show that aesthetic value was not an important aspect of usability survey. From this article also, we propose the most recent questionnaire of Usefulness, Satisfaction and Ease of use (USE) by Lund, which provide a 2: 1 questions on utilitarian and experiential respectively as a fair usability questionnaire. Those whom want to choose a 3: 1 questions on utilitarian and experiential may seeks for PSSUQ and SUMI usability questionnaires.

\section{APPENDIX}

TABLE V: THE ADDITIONAL WORDS GENERATED FROM MiCROSOFT WORD'S THESAURUS

\begin{tabular}{|l|l|c|}
\hline $\begin{array}{l}\text { Additional } \\
\text { Words }\end{array}$ & Similar Words & Attribute \\
\hline Clear & Well-Defined, Obvious, Tidy & $\mathrm{U}$ \\
\hline Comfortable & $\begin{array}{l}\text { Contended, Relaxed, Happy, Easy, } \\
\text { Calm }\end{array}$ & $\mathrm{U}$ \\
\hline Complex & Difficult, Complicated & $\mathrm{U}$ \\
\hline Cumbersome & Awkward, Weighty, Burdensome & $\mathrm{U}$ \\
\hline Confident & Self-assured, cool & EH \\
\hline Control & Management, Power, Charge & $\mathrm{U}$ \\
\hline Consistent & $\begin{array}{l}\text { Reliable, Steady, Constant, Stable } \\
\text { Coherent, Even, Uniform }\end{array}$ & $\mathrm{U}$ \\
\hline Difficult & $\begin{array}{l}\text { Problematic, Incomprehensive, Hard, } \\
\text { Obstinate }\end{array}$ & $\mathrm{U}$ \\
\hline Effective & $\begin{array}{l}\text { Operational, Applicable, Successful, } \\
\text { Useful }\end{array}$ & $\mathrm{U}$ \\
\hline Exploring & Investigating, Searching & $\mathrm{U}$ \\
\hline Feel & Experience, Think, Believe & EH \\
\hline Flexible & $\begin{array}{l}\text { Supple, Malleable, Adaptable, } \\
\text { Compliant, Docile }\end{array}$ & $\mathrm{U}$ \\
\hline Improve & Increase, Enhance, Enrich & $\mathrm{U}$ \\
\hline Like to use & Prefer, choose, approve & $\mathrm{EH}$ \\
\hline Learning & Studying & $\mathrm{U}$ \\
\hline Memorable & $\begin{array}{l}\text { Unforgettable, Notable, Striking, } \\
\text { Impressive, Remarkable }\end{array}$ & $\mathrm{U}$ \\
\hline Quickly & Rapidly, Fast, Speedily, Swiftly & $\mathrm{U}$ \\
\hline Pleasant & $\begin{array}{l}\text { Enjoyable, Pleasing, Satisfying, } \\
\text { Friendly, Nice }\end{array}$ & $\mathrm{EH}$ \\
\hline Productive & Helpful, Beneficial, Useful & $\mathrm{U}$ \\
\hline Recommend & Suggest, Propose & $\mathrm{UH}$ \\
\hline Rigid & Unbending, Inflexible, Firm \\
\hline Standard & Normal, Usual, Regular & $\mathrm{EH}$ \\
\hline Terrible & Awful, Horrible, Severe & \\
\hline
\end{tabular}

\section{ACKNOWLEDGMENT}

I would like to acknowledge the contribution given by two lecturers of National University of Malaysia for their involvements and contribution in helping the classification of the listed usability questionnaires. They are Dr. Tengku Siti Meriam and Dr. Siti Fadzilah Mat Noor.

\section{REFERENCES}

[1] H. Morten and C. Torkil, "How do usability professionals construe usability?" International Journal of Human-Computer Studies, vol. 70, no. 1, pp. 26-42, 2012.

[2] C. Laila, A. Alain, and S. Witold, "Harmonization of usability measurements in ISO9126 software engineering standards," in Proc. the IEEE International Symposium on Industrial Electronics, Montreal, Quebec, Canada, 2006.
[3] M. Sascha and T. Manfred, "Studying antecedents of emotional experiences in interactive contexts," in Proc. the SIGCHI Conference on Human Factors in Computing Systems, 2007.

[4] T. Noam and Z. Dror, "Exploring attributes of skins as potential antecedents of emotion in HCI," Aesthetic Computing, pp. 405-422, 2006.

[5] H. Marc, "The interplay of beauty, goodness, and usability in interactive products," Human-Computer Interaction, vol. 19, no. 4, pp 319-349, 2004

[6] K. Kristiina, "The beauty of simplicity," in Proc. Conference on Universal Usability, Washington, DC, USA, November 16 - 17, 2000.

[7] T. Noam, "Aesthetics and apparent usability: empirically assessing cultural and methodological issues," in Proc. the ACM SIGCHI Conference on Human Factors in Computing Systems, 1997, pp. $115-122$

[8] T. Noam, A. S. Katz, and I. Dror, "What is beautiful is usable," Interacting with Computers, vol. 13, no. 2, pp. 127-145, 2000

[9] R. D. Ward and P. H. Marsden, "Physiological responses to different web page designs," International Journal of Human-Computer Studies, vol. 59, no. 1, pp. 199-212, 2003

[10] H. Marc and M. Andrew, "The inference of perceived usability from beauty," Human-Computer Interaction, vol. 25, no. 3, pp. 235-260, 2010.

[11] A. N. Tuch, S. P. Roth, K. Hornbæk, K. Opwis, and J. A. Bargas-Avila, "Is beautiful really usable? Toward understanding the relation between usability, aesthetics, and affect in HCI," Computers in Human Behavior, vol. 28, no. 5, pp. 1596-1607, 2012.

[12] P. Van Schaik and J. Ling, "Modelling user experience with web sites: Usability, hedonic value, beauty and goodness," Interacting with Computers, vol. 20, no. 3, pp. 419-432, 2008

[13] A. Fernandez, E. Insfran, and S. Abrahão, "Usability evaluation methods for the web: A systematic mapping study," Information and Software Technology, vol. 53, no. 8, pp. 789-817, 2011.

[14] J. R. Lewis, "IBM computer usability satisfaction questionnaires: Psychometric evaluation and instructions for use," International Journal of Human - Computer Interaction, vol. 7, no. 1, pp. 57-78, 1995.

[15] J. R. Lewis, "Psychometric evaluation of an after-scenario questionnaire for computer usability studies: The ASQ," ACM SIGCHI Bulletin, vol. 23, no. 1, pp. 78-81, 1991.

[16] J. R. Lewis and J. Sauro, "The factor structure of the system usability scale," Human Centered Design Lecture Notes in Computer Science, vol. 5619, pp. 94-103, 2009.

[17] E. L. C. Law, P. Van Schaik, and V. Roto, "Attitudes towards user experience (UX) measurement," International Journal of Human-Computer Studies, vol. 72, no. 6, pp. 526-541, 2013.

[18] M. Thüring and S. Mahlke, "Usability, aesthetics and emotions in human-technology interaction," International Journal of Psychology, vol. 42, no. 4, pp. 253-264. 2007.

[19] K. Hornbæk and E. L. C. Law, "Meta-analysis of correlations among usability measures," in Proc. the SIGCHI Conference on Human Factors in Computing Systems, New York, 2007, pp. 617-626.

[20] J. Sauro and J. R. Lewis, "Correlations among prototypical usability metrics: evidence for the construct of usability," in Proc. the SIGCHI Conference on Human Factors in Computing Systems, 2009, pp 1609-1618.

[21] G. A. Churchill Jr, "A paradigm for developing better measures of marketing constructs," Journal of Marketing Research (JMR), vol. 16, no. 1, pp. 64, 1979.

[22] T. Christophersen and U. Konradt, "Reliability, validity, and sensitivity of a single-item measure of online store usability," International Journal of Human-Computer Studies, vol. 69, no. 4, pp 269-280, 2011

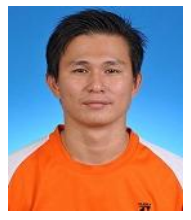

Tet Kun Chung was born in a small town named Keningau from state Sabah of Malaysia on June 5, 1980 He was given primary and secondary education in the town he was born and progress to form 6 at Kota Kinabalu, Sabah. He earned his first degree in science and education from the University of Malaya, Malaysia majoring in mathematics while minoring in biology at the year 2005 .

During his university period of 2001-2004, he joined the country's Reserve Officer Training Unit, navy division and was commission as a second lieutenant by the Royal Malaysian Navy in year 2004 but was decommissioned at the year 2006 due to inactive services. He proceed his career in teaching mathematics in middle school for 7 years starting year 2005 and now currently a full time master student at National University of Malaysia studying in Information Science since 2012. 